\title{
LESS IS MORE
}

\section{California's Energy Legacy \\ Art Rosenfeld}

One late Friday night in 1973 I conducted a small experiment that changed my life forever and that would have wideranging implications for California and, ultimately, the rest of the world.

Since I knew I would have to wait a half-hour in line to fill up my car with gasoline because of the oil embargo imposed by the Organization of Petroleum Exporting Countries (OPEC), I decided to go through the 20-office floor where I was working on the University of California campus and turn off all the lights I could get my hands on, and then calculate the energy savings.

A back-of-the-envelope calculation revealed that turning off the lights in my office alone-representing one kilowatt of electricity demand-saved the equivalent of 5 gallons of natural gas over the weekend that would have otherwise been burned in a power plant. It took me 20 minutes to find all of the light switches on my floor, many of which were hidden behind bookshelves and other obstructions, but this onetime act saved 100 gallons of fossil fuel in this single office floor over just one weekend!

Shortly thereafter, I teamed up with researchers in California, Princeton, and other U.S. universities and began to better understand why we Americans consumed such enormous 
quantities of energy when compared to our European and Japanese counterparts. The main reason was that energy was too cheap! Even today, in the twenty-first century, gasoline costs less than milk. Within just a week, my fellow researchers and I had discovered (some might say blundered into) a massive oil and gas field buried in our buildings, factories, and cars that could be extracted at costs far below what we were paying at the pump or at our electricity meters.

Thus began a revolution in thinking on energy. Given the mounting evidence regarding global climate change and its link to our fossil fuel addictions, it is a good time to take stock of how California has led the nation in doing more with less energy. Lessons learned here have helped wean the country from inefficient and polluting energy practices.

The United States has made impressive gains in reducing its wasteful habits, significantly improving its "energy intensity" (energy use per unit of gross domestic product). It is interesting to note that the "energy intensity" of the nation as a whole has dropped at five times the historical rate prior to the first oil embargo in 1973. This reduction compared to business-as-usual consumption levels equates to $\$ 700$ billion in annual savings. The corresponding reductions in the greenhouse gases linked to climate change represent the equivalent of taking one billion cars off the road. (To put that figure in perspective, consider the fact that there are roughly 600 million cars on the roads throughout the world right now.)

Since about two-thirds of these energy savings can be attributed to smart and extremely cost-effective public policies, the United States is saving roughly $\$ 500$ billion per year due to energy efficiency, about the same amount of taxpayer dollars invested in the Iraq war as of the end of 2006.

The vast majority of these savings and associated reduction in pollution are attributable to energy efficiency, a power supply choice pioneered and refined in California. California's leadership on energy matters has been followed 
by the United States as a whole as well as by other states and countries. Its appliance energy efficiency standards were ultimately copied by the federal government in 1987 . The state's building standards have recently been copied by Russia and China. Nonetheless, California will need to do more-much more, in fact--to deal with global warming. California is looking to accelerate and expand its trend-setting work on energy efficiency, renewable energy, cleaner forms of fossil fuel generation, the development of a "smart" electricity grid, and other technologies, practices, and behaviors.

To put the challenge facing California in perspective, consider that roughly $\$ 100$ billion is spent every year to power up the Golden State. The population of California has doubled since 1965, a rate of growth that exceeds all other comparable developed regions of the world. And the state Department of Finance projects that California's population will swell to almost 60 million by 2050 .

California's enormous energy appetite translates into the unfortunate reality that we put a lot of stuff in the air that contributes to global climate change. No doubt California has served as a model in cutting pollution and in developing new alternative sources of energy. California adopted stringent tailpipe emission standards for motor vehicles as early as 1966. Before the oil crisis of the 1970s, over half of the electricity supplied in the state came from burning petroleum, a legacy of the state's geologic history and enthusiastic exploitation. Today, clean-burning natural gas provides over 40 percent of the fuel for power plants, while the state's portfolio of renewable sources is expanding to meet a state policy goal of 20 percent of total electricity supply by 2010 .

Despite such notable strides-and the aforementioned aggressive energy efficiency program that led the nationCalifornia ranks second among the United States (behind Texas) in terms of greenhouse gas emissions, with approximately 500 million metric tons (MMT). The passage of 
AB 32, the Global Warming Solutions Act of 2006, requires California to cut greenhouse gas emissions by 29 percent by 2020. Since 81 percent of California's contribution to climate change comes from the combustion of fossil fuels, it's no secret where the state and the world need to go in the future.

But how to get there? That's the real question, and there is still considerable debate on this weighty topic, given past investments in infrastructure, current costs of alternative energy sources, and a host of interconnected and complex challenges.

This book by journalist and consultant Peter Asmus, who has been covering state, national, and global energy developments for two decades, represents a primer on all energy sources, including controversial ones, such as nuclear reactors and liquefied natural gas, that have made recent headlines. It also reveals the rich human history of California's earliest energy developments with oil and hydroelectricity, as well as the natural history underpinnings of this state's cornucopia of energy sources. By combining history with an up-to-date assessment of potential energy answers, this book is invaluable as a resource for those wanting to become part of the solution to our present day energy challenges. Free of jargon and political posturing, this book provides a frank and sobering view of the conundrum of energy. It also is filled with scientific facts that will allow the reader to make up their own minds about which resources can help fuel a more sustainable energy future.

Among the prime messages of this book is that we can do more with less. Solar, wind, and the other renewable supply options are all vitally important, as are other advances in fossil fuels and perhaps other traditional forms of energy production. Yet energy efficiency is the cheapest and cleanest form of energy. California and the rest of the nation, as well as the entire world, should reduce wasteful consumption first and foremost, and then turn to the supply choices that have 
dominated debates about the age-old question of energy, the primordial essence of modern society. The timing for such a book could not be better. It is my hope that readers come away with a profound appreciation of the role California has played in energy trends, and the critical work that lies ahead for all of us. 
